\title{
Entomopathogenic fungi, Metarhizium anisopliae and Beauveria bassiana reduce the survival of Xenopsylla brasiliensis larvae (Siphonaptera: Pulicidae)
}

\author{
Ladslaus L Mnyone ${ }^{1,2^{*}}$, Kija R Ng'habi $^{1}$, Humphrey D Mazigo ${ }^{3}$, Abdul A Katakweba $^{2}$ and Issa N Lyimo ${ }^{1}$
}

\begin{abstract}
Background: Entomopathogenic fungi, particularly those belonging to the genera Metarhizium and Beauveria have shown great promise as arthropod vector control tools. These agents, however, have not been evaluated against flea vectors of plague.

Findings: A 3-h exposure to the fungi coated paper at a concentration of $2 \times 10^{8}$ conidia $\mathrm{m}^{-2}$ infected $>90 \%$ of flea larvae cadavers in the treatment groups. The infection reduced the survival of larvae that had been exposed to fungus relative to controls. The daily risk of dying was four- and over three-fold greater in larvae exposed to $M$. anisopliae ( $H R=4, p<0.001)$ and $B$. bassiana $(H R=3.5, p<0.001)$ respectively. Both fungi can successfully infect and kill larvae of $X$. brasiliensis with a pooled median survival time (MST \pm SE) of $2 \pm 0.31$ days post-exposure.

Conclusion: These findings justify further research to investigate the bio-control potential of entomopathogenic fungi against fleas.
\end{abstract}

\section{Findings}

Plague is a zoonotic disease caused by Yesinia pestis, one of the most pathogenic bacteria [1]. Plague may occur in three forms: bubonic, septicaemic and pneumonic plague. Without prompt and appropriate treatment, plague, especially the two latter forms, is virtually always fatal. This disease remains an extremely important public health concern in many parts of the world. Strikingly, however, over $90 \%$ of all cases and deaths reported to date occur in Africa [2]. The most seriously affected countries are Mozambique, Malawi, Uganda, Madagascar, Democratic Republic of Congo and Tanzania. For example, Lushoto, one of the most active plague foci, plague outbreaks that have occurred from 19802003 involved about 7000 reported cases/suspects with over 630 (9\%) deaths [3].

\footnotetext{
* Correspondence: Ilaurent@ihi.or.tz

${ }^{1}$ Biomedical and Environmental Thematic Group, Ifakara Health Institute, P.O. Box 53, Off Mlabani Passage, Ifakara, Tanzania

${ }^{2}$ Pest Management Centre, Sokoine University of Agriculture, P.O. Box 3110, Morogoro, Tanzania

Full list of author information is available at the end of the article
}

Plague can be transmitted from small mammals particularly rodents to humans through flea bites. Among others, common flea vectors include Xenopsylla cheopis, $X$. brasiliensis, Dinopsyllus lypusus and Pulex irritans [1]. Control of flea vectors remain the mainstay of plague control in many countries. Vector control has greatly contributed in reducing severity of plague transmission and/or outbreaks. However, several problems may be associated with recurring plague. Firstly, drastic climate change and less global commitment to the disease might escalate the risk of plague outbreaks. Secondly, high operational costs as a result insecticides are applied only during and soon after disease outbreaks and yet are not always done promptly and sufficiently. Lastly, the development of insecticide resistance in fleas that in turn threatens sustainability of control strategies. Insecticide resistance in fleas has been reported in Tanzania and globally [4,5]. Insecticide resistance has greatly affected the global efforts to control and possibly eliminate mosquito borne diseases such as malaria [6,7]. The extent of the problem of insecticide resistance in fleas is currently low, however, it would be quite 
advantageous to learn from the situation in malaria and prevent it from happening in plague. Clearly, immediate efforts to develop effective and cheap complementary flea control strategies are necessary. The aim should be to develop control strategies, which can synergize with the existing ones; and are less likely to suffer from the problem of resistance.

Entomopathogenic fungi, particularly those belonging to the genera Metarhizium and Beauveria have shown great promise as arthropod vector control tools [8-10]. These fungi are soil-borne and predominantly infect soil dwelling insects [11]. These agents, however, have not been evaluated against flea vectors despite the fact that the latter (especially pre-mature stages) prefer soil microhabitats. Therefore, preliminary study was conducted to demonstrate if $M$. anisopliae and $B$. bassiana can infect and kill larval stages of fleas, $X$. brasiliensis.

Two fungal isolates were used: Metarhizium anisopliae ICIPE-30 and Beauveria bassiana IMI 391510. Dry conidia of the fungi were suspended in highly refined enerpar M002 oil (BP Southern Africa LTD) to obtain a test solution. A total of $1200 \mu \mathrm{l}$ of the test solution was applied evenly to a $15 \times 25 \mathrm{~cm}$ piece of painting paper using a metal bar $(0.31 \mathrm{~mm}$ diameter; paper and applicator bar from RK Print Coat Instruments, London) [9] giving a uniform concentration $2 \times 10^{8}$ conidia $\mathrm{m}^{-2}$. Untreated control replicates used paper with enerpar only. After drying (24 h at room temperature), paper was cut circumferentially to fit inside Petri dishes without scraping the conidia off.

Flea larvae reared at Sokoine University of Agriculture Pest Management Centre insectary (SPMC) were exposed to treated and untreated paper inside a Petri dish in three replicates; 20 larvae per replicate. The larvae were held in the Petri dish for $3 \mathrm{~h}$, after which they were transferred to transparent holding containers containing a mixture of sterile sand and ground dry cow blood. The survival and fungus infection status of larvae were monitored daily for up to $15 \mathrm{~d}$ following procedures described elsewhere [8]. They were maintained at $27.5 \pm 2.5^{\circ} \mathrm{C}$ and $\geq 82 \% \mathrm{RH}$. The survival of flea larvae was analyzed by Cox regression analysis, using SPSS version 16. Cox regression generated hazard ratios (HR) indicating the daily risk of dying for larvae in each treatment and control. Kaplan-Meier pairwise method was used to obtain median survival times (MST) for treated and untreated flea larvae.

M. anisopliae and B. bassiana were capable of infecting $>90 \%$ of $X$. brasiliensis larvae (fungal growth on cadavers observed after incubation for 4-6 d). Both fungal isolates significantly reduced the survival of all exposed larvae compared to controls (Figure 1); 100\% mortality in exposed larvae was achieved in $9 \mathrm{~d}$ for $M$. anisopliae and $11 \mathrm{~d}$ for B. bassiana. In the control, $>94 \%$ of larvae were still alive by $15 \mathrm{~d}$ and most had transformed to pupae; and none of the cadavers showed fungal sporulation. For M. anisopliae, the daily risk of dying was four-fold greater in exposed larvae relative to their controls $(\mathrm{HR}=4, p<0.001)$. For $B$. bassiana, the daily risk of dying was over three-fold greater in exposed larvae relative to their controls $(\mathrm{HR}=3.5, p<0.001)$. However, the survival of flea larvae exposed to either fungus was equally reduced $\left(x^{2}=3.45, p>0.05\right)$; median survival time (MST $\pm \mathrm{SE}$ ) of larvae exposed to $M$. anisopliae and B. bassiana was $2 \pm 0.33 \mathrm{~d}$ and B. bassiana $2 \pm 0.31 \mathrm{~d}$ respectively. The MST for controls could not be estimated because mortalities did not exceed 50\%.

Biological control agents that can effectively be delivered to target flea larvae could be a potential complementary approach to existing control strategies. Here we have shown for the first time that dry conidia of $M$. anisopliae and $B$. bassiana formulated in enerpar oil can infect and kill larvae of $X$. brasiliensis; $100 \%$ mortality in exposed larvae was achieved in $9 \mathrm{~d}$ for $M$. anisopliae and $11 \mathrm{~d}$ for $B$.
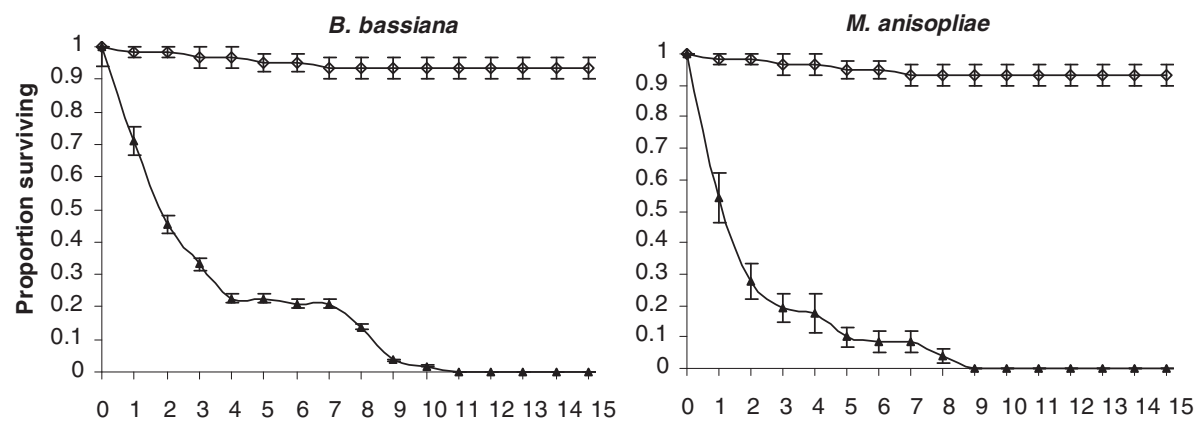

Days post exposure

$\rightarrow$ Treated $\rightarrow$ Control

Figure 1 Survival of Xenopsylla brasiliensis larvae after $3 \mathrm{~h}$ exposure to entomopathogenic fungi, Metarhizium anisopliae ICIPE-30 and Beauveria bassiana 193-825. 
bassiana. Similar rates of mortality have been reported when fungi were tested against other arthropods [12,13]. Perhaps, most importantly, fungi have multifaceted mode of action and cause delayed mortality. As such, these agents would pose less selection pressure for development of resistance [14] against fleas; and thus offer an alternative to chemical insecticides. Although insecticide resistance in fleas is currently not that alarming, it is important to invest in developing resistance management strategies before the situation worsens. Integrating entomopathogenic fungi with chemicals, could delay resistance development and thus extend the lifetime of insecticidal control strategies [15]. Interestingly, these fungi have been found to equally infect insecticide resistant anopheline mosquitoes $[16,17]$. This could equally be a possibility in flea vectors. Other advantages of fungi include cost effectiveness [15] and minimum risk to the environment and living organisms [16].

Over $90 \%$ of treatment larvae showed fungal growth after death. In view of the nature of fleas' soil microhabitats, similar infection rates could occur in nature and thus allow dissemination of conidia to uninfected individuals. Uninfected eggs, larvae, pupae and adult fleas may get infected from auto-disseminated conidia from the sporulating cadavers and contaminated microhabitats. Interestingly, all the immature and mature stages of fleas share similar microhabitats at some point, which maximizes the chance of infecting all stages. Flea microhabitats are often cooler, humid and normally protected from direct sunlight (e.g. rodent burrows). Arguably, such environments will allow fungal conidia to remain infective for relatively longer periods. Equally important, self propagation of fungal propagules might be a possibility. The effect of environmental factors on fungal potency is probably the most fundamental challenge that may interfere with the field use of fungi.

We envisage that, the revealed ability of $M$. anisopliae and $B$. bassiana to reduce survival of flea larvae will stimulate research to further investigate the flea control potential of these biological control agents. Studies to fully understand both lethal and sub-lethal effects of fungi on not only flea larvae, but also eggs and adults, are justifiable.

\section{Competing interests}

All authors have no competing interest to declare and all have actively contributed to this study and review.

\section{Authors' contributions}

Conceived and designed the experiments: LLM BSK INL HDM. Performed the experiments: LLM AAK. Analyzed the data: LLM INL HDM. Wrote the paper: LLM INL KRN AAK. Reviewed the paper: BSK CL. All authors read the final version of the manuscript.

\section{Acknowledgements}

We wish to acknowledge Shabani Lutea, Halima Mbaga and Michael Sanga for rearing fleas and providing technical assistance.

\section{Author details}

${ }^{1}$ Biomedical and Environmental Thematic Group, Ifakara Health Institute, P.O. Box 53, Off Mlabani Passage, Ifakara, Tanzania. ${ }^{2}$ Pest Management Centre, Sokoine University of Agriculture, P.O. Box 3110, Morogoro, Tanzania.

${ }^{3}$ Department of Medical Parasitology and Entomology, Faculty of Medicine, Weill-Bugando University College of Health Sciences, Mwanza, Tanzania, P.O. Box 1464, Mwanza, Tanzania.

Received: 18 May 2012 Accepted: 29 August 2012

Published: 19 September 2012

\section{References}

1. Laudisoit A, Leirs H, Makundi RH, Van Dongen S, Davis S, Neerinckx S, Deckers J, Libois R: Plague and the human flea, Tanzania. Emerg Infect Dis 2007, 13:687-693.

2. Tikhomirov E: Epidemiology and distribution of plague. In Plague Manual: Epidemiology, Distribution, Surveillance and Control. Edited by Dennis DT, Gage KL, Gratz NG, Poland JD, Tikhomirov E. Geneva: WHO; 1999:11-41.

3. Kilonzo BS, Mvena ZSK, Machangu RS, Mbise TJ: Preliminary observation on factors responsible for long persistence and continued outbreaks of plague in Lushoto district, Tanzania. Acta Trop 1997, 68:215-227.

4. El-Gazzar LM, Milio J, Koehler PG, Patterson RS: Insecticide resistance in the cat flea (Siphonaptera: Pulicidae). J Econ Entomol 1986, 79:132-134.

5. Kilonzo BS, Mutasa JA: Baseline susceptibility/resistance levels of Xenopsylla cheopis and Ctenocephalides felis to DDT and Dieldrin in Morogoro District, Tanzania. Tanzania Vet Bull 1989, 9:28-33.

6. Kelly-Hope L, Ranson H, Hemingway J: Lessons from the past: managing insecticide resistance in malaria control and eradication programmes. Lancet Infect Dis 2008, 8:387-389.

7. N'Guessan R, Corbel V, Akogbéto M, Rowland M: Reduced efficacy of insecticide-treated nets and indoor residual spraying for malaria control in pyrethroids resistance area, Benin. Emerg Infect Dis 2007, 13:199-206.

8. Mnyone LL, Kirby MJ, Lwetoijera DW, Mpingwa MW, Knols BGJ, Takken W, Russell TL: Infection of the malaria mosquito, Anopheles gambiae with two species of entomopathogenic fungi: effects of concentration, co-formulation, exposure time and persistence. Malaria J 2009, 8:309.

9. Mnyone LL, Russell TL, Lyimo NI, Lwetoijera DW, Kirby MJ, Luz C: First report of Metarhizium anisopliae IP 46 pathogenicity in adult Anopheles gambiae s.s. and An. arabiensis (Diptera; Culicidae). Parasit Vectors 2009, 2:59.

10. Lwetoijera DW, Sumaye RD, Madumla EP, Kavishe DR, Mnyone LL, Russell TL, Okumu FO: An extra-domiciliary method for delivering entomopathogenic fungi, Metarhizium anisopliae IP 46 against malaria vectors, Anopheles arabiensis. Parasit Vectors 2010, 3:18.

11. Keller S, Zimmermann G: Mycopathogens of soil insects. In Insect-fungus interactions. Edited by Wilding N, Collins NM, Hammond PM, Webber JF. UK: Academic Press London; 1989:240-270.

12. Blanford S, Chan BHK, Jenkins N, Sim D, Turner RJ, Read AF, Thomas MB: Fungal pathogen reduces potential for malaria transmission. Science 2005, 308:1638-1641.

13. Farenhorst M, Farina D, Scholte EJ, Takken W, Hunt RH, Coetzee M, Knols $B G J$ : African water storage pots for the delivery of the entomopathogenic fungus Metarhizium anisopliae to the malaria vectors Anopheles gambiae s.s. and Anopheles funestus. AmJTrop Med Hyg 2008, 78:910-916.

14. Read AF, Lynch PA, Thomas MB: How to make evolution-proof insecticides for malaria control. PLOS Biol 2009, 7:e1000058.

15. Ffrench-Constant $\mathrm{RH}$ : Something old, something transgenic, or something fungal for mosquito control? Trends Ecol Evol 2005, 20:577-579.

16. Farenhorst M, Mouatcho JC, Kikankie CK, Brooke BD, Hunt RH, Thomas MB, Koekemoer LL, Knols BGJ, Coetzee M: Fungal infection counters insecticide resistance in African malaria mosquitoes. Proc Natl Acad Sci USA 2009, 106:17443-17447.

17. Howard AFV, Koenraadt CJM, Farenhorst M, Knols BGJ, Takken W: Pyrethroid resistance in Anopheles gambiae leads to increased susceptibility to entomopathogenic fungi Metarhizium anisopliae and Beauveria bassiana. Malaria J 2010, 9:168.

doi:10.1186/1756-3305-5-204

Cite this article as: Mnyone et al.: Entomopathogenic fungi, Metarhizium anisopliae and Beauveria bassiana reduce the survival of Xenopsylla brasiliensis larvae (Siphonaptera: Pulicidae). Parasites \& Vectors 2012 5:204. 